\title{
تأثير استخدام أنموذج التعلم البنائي في التحصيل المعرفي وتعلم مهارة الاحرجة بكرة القدم \\ لطلاب الصف الثاني متوسط
}

علي صلال نايف(1)، محمد عبدالحسين عطية(2)

تأريخ تقديم البحث: (2020/5/19)، تأريخ قبول النشر (2020/6/16).

DOI: https://doi.org/10.37359/JOPE.V32(2)2020.997

المستخلص

تكمن اهمية البحث في تأثير استخدام انموذج التعلم البنائي في تتمية التحصيل المعرفي وتعلم مهارة الدحرجة بكرة القدم لطلاب الصف الثاني متوسطو تطرق الباحثان الى مشكلة البحث من خلال الطريقة المنبعة من قبل المدرس و القائمة على أساس الإمتثال

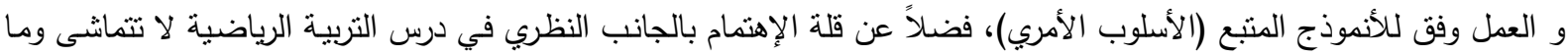

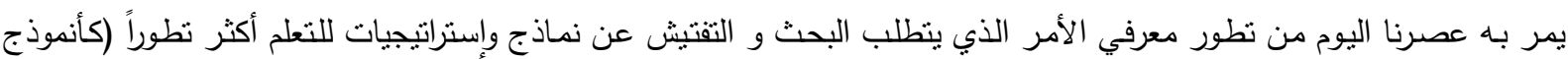
التعلم البنائي) وكان الهذف من البحث هو التعرف على تأثير استخدام أنموذج (التعلم البنائي) في التحصيل الهعرفي وتعلم مهارة الدحرجة بكرة القدم لطـلاب الصف الثناني متوسط، واستخدم الباحثان التصميم التجريبي ذات المجهوعتين المتكافئة ( التجرييية والظابطة) ذات الأختبار القبلي والبعدي لملائمته لطبيعة مشكلة البحث وأهدافه ، وتم تطبيق مفردات البحث على عينة البحث البالغ

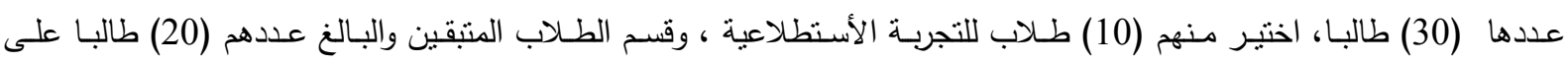

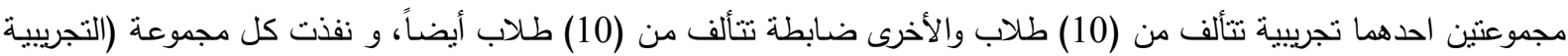
والظابطة) منهجها النعليمي كلأتي المجموعة التجريبية بأنموذج التعلم البنائي الهجوعة الظابطة الطريقة التقليدية المتبعة من قبل مدرس التربية الرياضية والبدنية، واستغرقت الدراسة ثمانية أسابيع وتضمنت وحدتين تعليميتين في الأسبوع الواحد لكل مجموعة، زمن

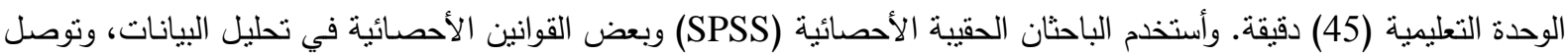

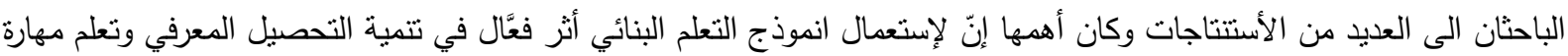

$$
\text { الدحرجة بكرة القدم لاى طلاب الصف الثان من الثاني منوسط. }
$$

الكلمات المفتاحية: انموذج التعلم البنائي، التحصيل المعرفي، مهارات كرة القدم.

\section{ABSTRACT \\ The Effect of Constructive Learning Model on Cognitive Achievement and Learning dribbling Skill in Soccer for Secondary School Students}

The research aimed at identifying the effect of using constructive learning model on academic achievement and learning soccer dribbling Skill in 2nd grade secondary school students. The researcher used the experimental method on (30) secondary school students; 10 selected for pilot study, 20 were divided into two groups. The experimental group followed constructive learning model while the controlling group followed the traditional method. The experimental program lasted for eight weeks with two teaching sessions per week for each group. The data was collected and treated using SPSS to conclude the positive effect of using constructive learning model on developing academic achievement and learning soccer dribbling Skill in 2nd grade secondary school students. Finally the researchers recommended benefiting from constructive learning model in improving and learning dribbling Skill.

Keywords: Cognitive Achievement, constructive learning model, soccer skills.

(1) طالب دراسات عليا (الدكتوراه)، جامعة بغداد، كلبة التربية البننية وعلوم الرياضة. (Iali07500@gmial.com) Ali Salal Naif, Post Graduate Student (P.HD), University of Baghdad, College of Physical Education and Sport Sciences, (lali07500@gmial.com) (+964771137152).

(2) أستاذ، دكتوراه تربية رياضية، جامعة بغداد، كلية التربية البنية وعلوم الرياضة (Mohamedalmuktar1972@gmial.com). Muhameed Abdul Hussein Atia, Prof (PH.D), University of Baghdad, College of Physical Education and Sport Sciences, (Mohamedalmuktar1972@gmial.com) (+964770924048). 
أصبح مفهوم العملية التعليمية الحديثة يركز على انتقال العملية التعليمية من المعلم للمتعلم، فيكون دور المعلم هو موجه ومرشد بحيث يوجه نشاط تلاميذه نوجيها يمكنهم الاعتماد على أنفسهم لتسهيل عملية التعلم من خلال جعل المتعلم

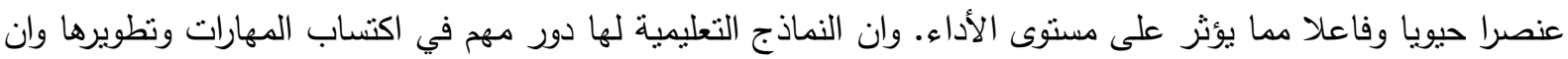

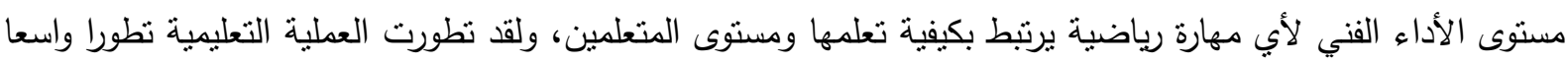

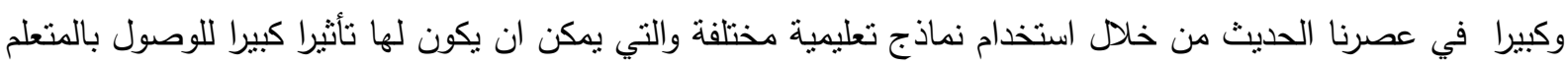
الى مستوى مهاري افضل، وأجريت العديد من البحوث التي سعت الى إيجاد طرق ونماذج مؤثرة في عملية التعلم الحديثة

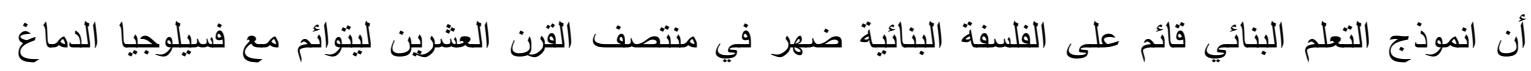
البشري لتجسد مفهوم التعلم كعلية بناء، فهو يرتكز على ان المتعلم محور العملية التعلمية ويبني معرفته من خلال تفاعله فئه

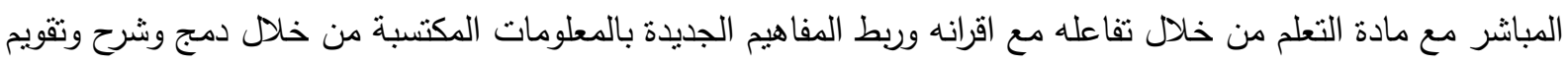
المعلم للمادة المتعلمة لكي يحدث تغيرات في بنية المتعلم المعرفية على أساس المعاني الجديدة من خلال مراحله الأربع (الدعوة، الأستكثاف، التقسير والحلول، اتخاذ القرار)، وتطرق الباحثان الى مشكلة البحث من خلال الطريقة المتبعة من

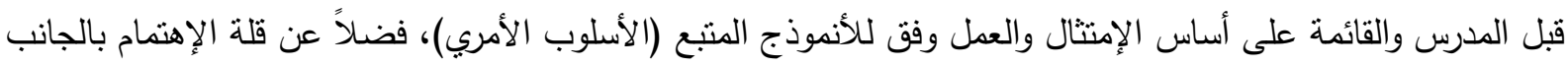

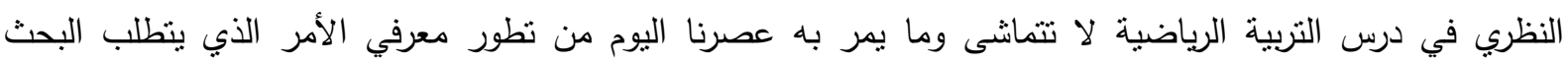

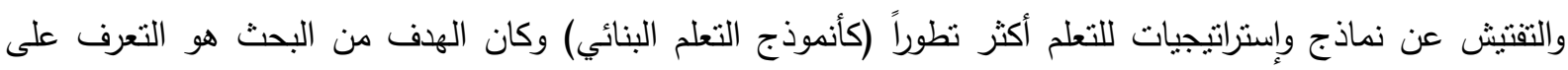

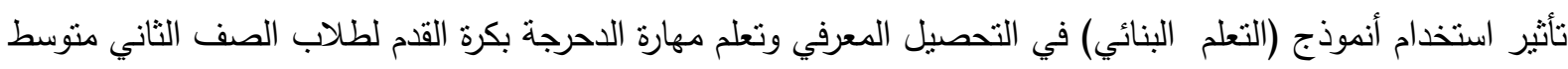
وقد تطرقت العديد من الدراسات حول النماذج البنائية ومهارات كرة القدم ومنها دراسة (ثامل، 2019) والتي توصلت فئت

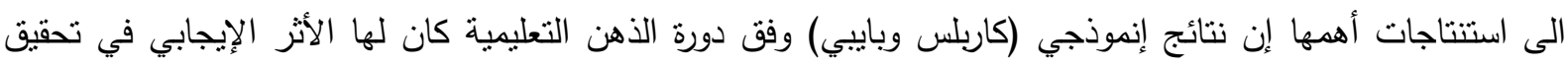

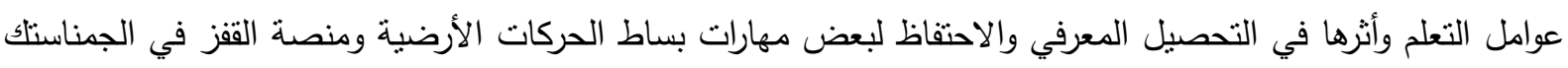
للطلاب وبدلالة الاختبارات القبلية والبعدية لمجاميع البحث التجريبيتين والضابطة. ونتين النتائج إن إنموذج (بايبي) ذات المراحل الخمس يناسب وبشكل كبير لطلاب كلية التربية البدنية وعلوم الرياضة، إذ بيَّنت النتائج أنه يتمانشى مع قابلياتهم الذهنية والحركية. أيضا بيَّنت النتائج أن أنموذجي (كاربلس) و (بايبي) أعطت مقداراً كبيراً في نسب الاحتفاظ مما يؤهل

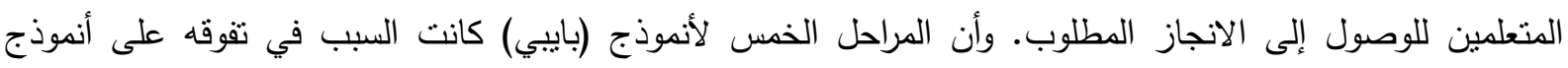
(كاربلس) وذلك من خلال توسيع البنية المعرفية لديهم عبر مراحله والتي تتعكس إيجابياً على إدائهم الحركي وتحصيلهم لإنه المعرفي ونسب الاحتفاظ.

اما دراسة (ترف، 2014) فقد توصلت إلى أهمها المنهاج التعليمي المصمم على وفق استراتيجية التعلم البنائي اثبت أهميته وفاعليته لذوب التفكير الحاذق في تعلم مهارتي الضرب الساحق وحائط الصد بالكرة الطائرة بشكل افضل من التصن

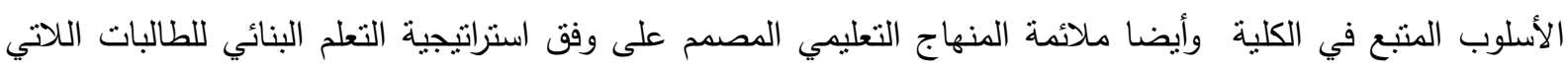
يمتلكن تفكيرا حاذقا قد حقق نتائج افضل في تعلم مهارتي الضرب الساحق وحائط الصد بالكرة الطائرة بشكل افضل من فئن الأسلوب المتبع في الكلية فضلا عن ذلك ان الطالبات اللاتي يمتلكن تفكيرا حاذقاً في المجموعة التجريبية لايهم القابلية على التعلم بشكل افضل من الطالبات اللواتي لا يمنلكن تفكيرا حاذقا في المجموعة نفسها و ان الطالبات اللاتي يمنلكن تفكيرا حاذقا في المجموعة الظابطة لديهن القابلية على التعلم بثكل افضل من الطالبات اللواتي لا يمتلكن تفكيرا حاذقا في المجموعة نفسها.

اما دراسة (خضير، 2017) فقد نوصلت الى إنّ لإستعمال إستراتيجية سوم (SWOM) أثز فعَّال في تطوير و

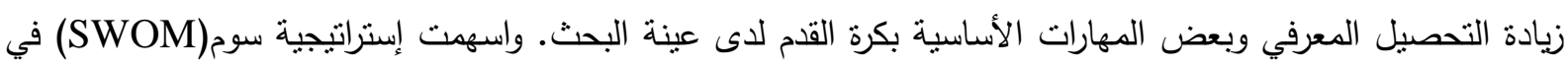

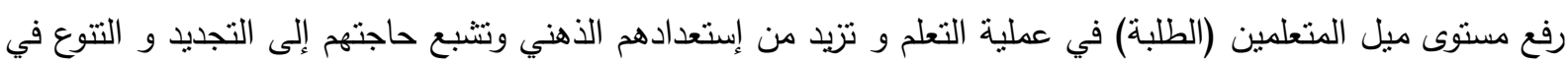


طرائق التدريس. فضلا عن ذلك أنه يُكن إعتماد إستراتيجية سوم (SWOM) في تعليم المهارات الأساسية بكرة القدم وفي تطوير التحصيل المعرفي لدى الطلاب؛ لإنهّما تشجع الطلاب على تقصي المعلومات و الحقائق وجعل الطالب يفكر بالأداء قبل القيام به. وإنّ الطريقة الإعنيادية في التعلم من الطرائق التي لا يُمكن الإستغناء عنها ويُمكن أن تُعطي نتائج جيدة إذا وجا

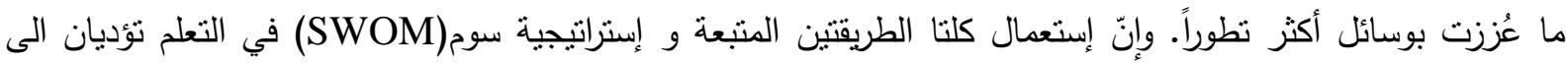

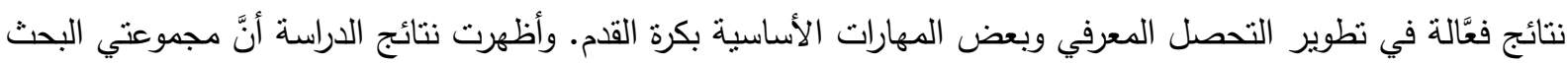
(التجريبية و الضابطة) قد حققت نطوراً في التحصيل المعرفي وبعض المهارات الأساسية بكرة القدم ولكن بنسب متفاوتة. وتفوقت الهموعة التجريبية والتي تعلَّت بإستعمال إستراتيجية سوم (SWOM) على المجموعة الضابطة في المهارات قيد

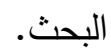
اما الدراسة الحالية فأنها محاولة لتوجيه أنظار المختصين للاهنمام بتعليم المهارات الرياضية وفق (انموذج التعلم البنائي) كون هذا الأنموذج يسهم في تعليم وتطوير الاداء الحركي من خلال تتمية التفكير والاستكثاف لدى المتعلمين فضلا عن ان هذه النموذج يعد من النماذج التعليمية النشطة التي قد تُثير إهتمام الطلبة و تدفعهم للتعلم و تثتوقهم للمعرفة والمُشاركة الفعَّالة مع المدرس.

\section{الطريقة والأدوات:}

استعمل الباحثان المنهج التجريبي بتصميم المجموعنين المتكافئة (التجريبية والظابطة) ويعد المنهج التجريبي من اكثر

مناهج البحث العلمي كفاءة ودقه ويرتبط هذا بمجموعة من الخصائص والمميزات التي يتمتع بها هذا المنهج. هدف البحث الى استخدام (انموذج التعلم البنائي) في تعلم مهارة الدحرجة في كرة القدم وتتمية الجانب المعرفي لطلاب

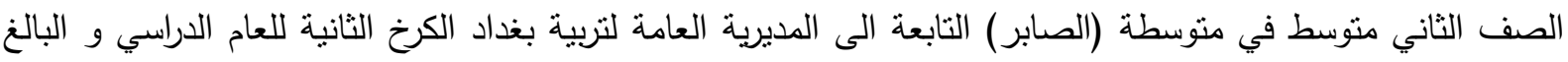

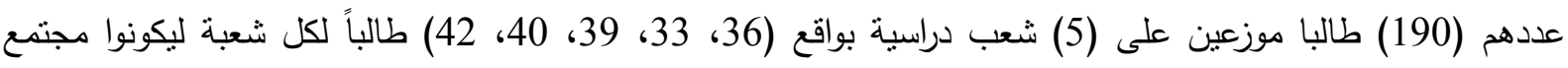
البحث، وتم اختيار (30) طالبا كعينة إذ تم اختبارها عشوائياً، وتم اختيار (10) طلاب للتجربة استطلاعية، تقسيم بقية العينة الى مجموعنين: المجموعة التجريبية (10) طلاب، والمجموعة الظابطة (10) طلاب كما وقام بأيجاد تكافؤ ونئ

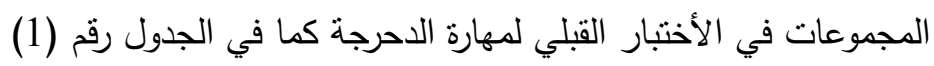

الجدول (1) يبين تكافؤ المجموعات في الاختبار القلبي لمهارة الدحرجة

\begin{tabular}{|c|c|c|c|c|c|c|}
\hline \multirow{2}{*}{ مستوى الخطأ } & \multirow{2}{*}{ ت المحسوبة } & \multicolumn{2}{|c|}{ المجموعة الضابطة } & \multicolumn{2}{|c|}{ المجموعة التجريبية } & \multirow{2}{*}{ ل لمتغيرات } \\
\hline & & $\varepsilon$ & 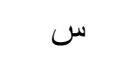 & $\varepsilon$ & س س & \\
\hline 0.988 & 0.507 & 0.90880 & 5.7000 & 1.28620 & 5.6667 & الاحرجة \\
\hline
\end{tabular}

معنوي > (0.05)

وتمثل الاختبار المهاري باختبار الدحرجة بين (5) شواخص. (محسن، 1990، صفحة 160)

كما تم استخدام اختبار التحصيل المعرفي والذي هو عبارة عن اختبار نوع الورقة والقلم ويهدف الى التعرف على المفاهيم

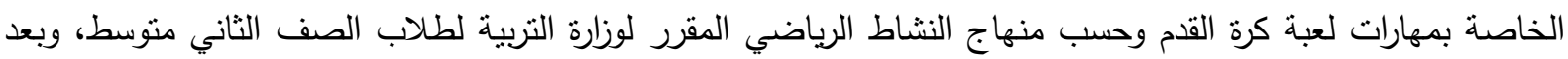
اطلاع الباحث على البحوث والمصادر السابقة (خضير، 2017) (الحسين، 2005) استفاد الباحث منها في عدة فقرات تتاسب مستوى عينة البحث. وتم بناء هذا الأختبار بصيغته النهائية حيث اقتزح الباحثان مجموعة فقرات ليتم اضافتها الى الفقرات السابقة التي تم

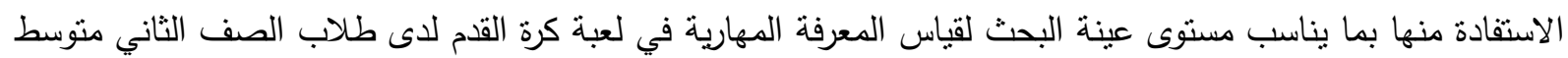
وذللك باستخدام أسلوب الأختيار من متعدد ، وتم اجراء المعاملات العلمية ( الصدق - الثبات - الموضوعية). 
وللتوصل الى افضل طريقة لتتفيذ إجراءات البحث الميدانية قام الباحثان بأجراء ثلاث تجارب اسنطلاعية على مجموعة

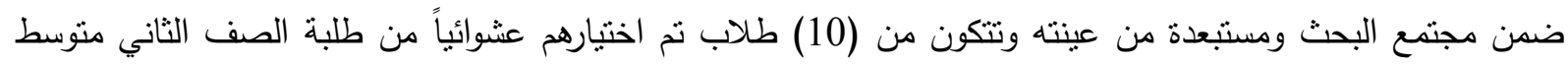

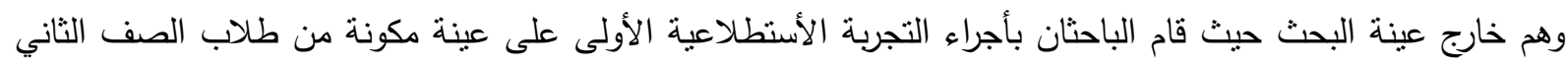
منوسط وذلك في بتاريخ (2019/2/18) وهم خارج عينة البحث وذللك للتعرف على مدة الزمن اللازم للاختبار ، وتتظيم

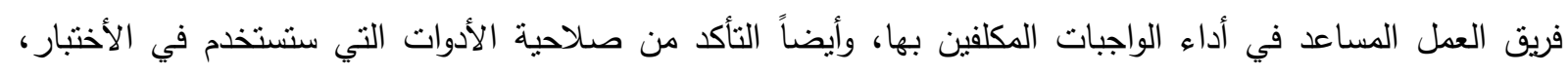

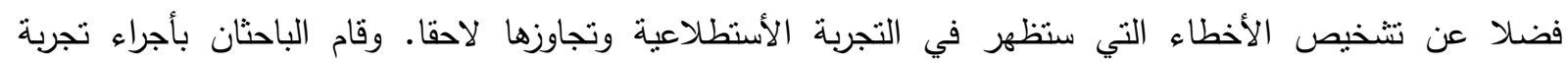
استطلاعية ثانية وذلك في بتاريخ (2019/2/19) والخاصة بأختبار التحصيل المعرفي المتكون من مجموعة أسئلة خاصة بمهارة الدحرجة، الذي نت تحديد فقراته من قبل المختصين بهذا المجال، على عينة من الصف الثاني متوسط لمتوسطة معاذ ابن جبل وذلك لغرض التعرف على مدة الزمن المستغرق واللازم للأداء (توزيع ورقة الأختبار ، والتعليمات، والأجابة، وجمع الأستمارات)، والتعرف على ملائمة مستوى فقرات الاختبار لمستوى العينة وقدرتهم على الأجابة عليه ومدى ملائمة

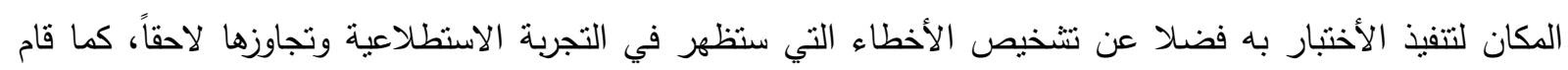
الباحثان بأجراء التجربة الأستطلاعية الثالثة وذلك بتاريخ (2019/2/20) والخاصة بالوحدات التعليمية وفق انموذج التعلم البنائي على عينة من طلاب من الصف الثاني منوسط وهم خارج عينة البحث وذلك للتعرف على إمكانية تطبيق انموذج التعلم البنائي والأدوات المستخدمة في الوحدة التعليمية، وكذللك لحتساب السقف الزمني للوحدات التعليمية. وتم اجراء الأختبارات القبلية لمهارة الدحرجة بكرة القدم لمعرفة مستوى المختبرين قبل البداء بالتجربة، ثم قام الباحثان

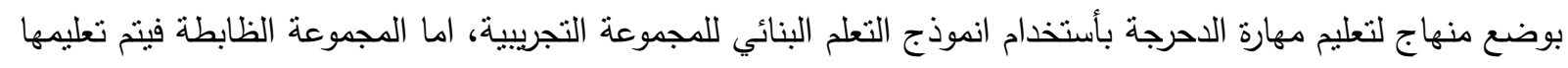

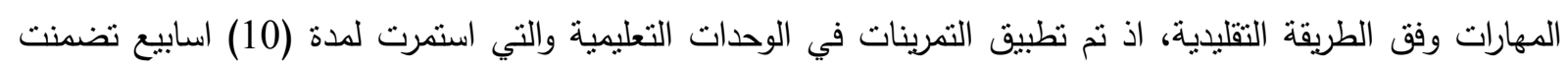
(20) وحدة تعليمية بواقع (2) وحدة في الأسبوع، زمن الوحدة التعليمية الواحدة (45) دقيقة وزمن القسم الرئيسي (32) دقيقة، مقسمة الى (17) دقيقة للقسم التعليمي و (15) دقيقة للقسم التطبيقي. وتعلمت المجموعة التجريبية الأولى وفق انموذج التعلم البنائي والذي يتكون من اربع مراحل والتي يكون فيها للطالب دفي دئي دور مهم في انجاح عملية التعلم وبعد القيام بالاحماء في الجزء التحضيري يدخل المدرس الى القسم الرئيسي وأول مرحلة من مراحل هذا الأنموذج هي مرحلة الدعوة ففي هذه المرحلة يبدأ المدرس بحوار مع طلابه حول المفهوم المراد تعلمه فيه

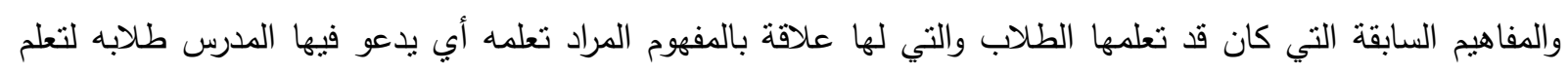

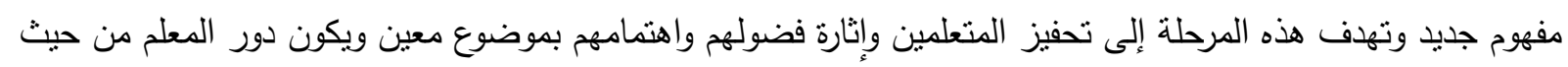

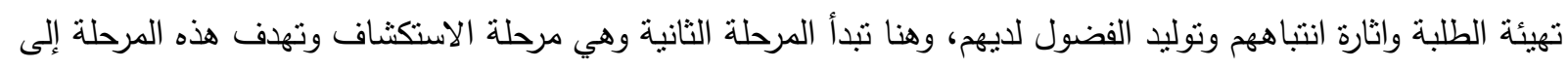

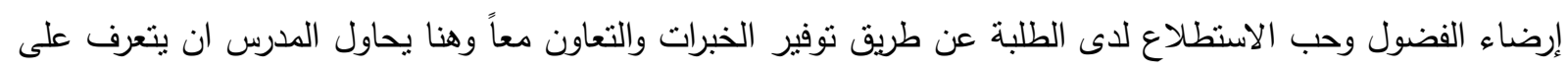

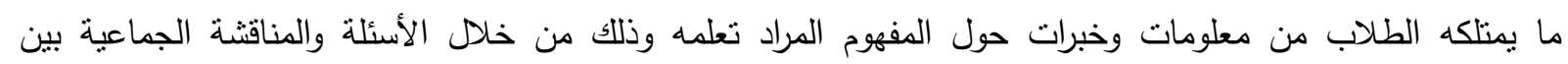
المتعلمين حول المفهوم الجديد والتي تكون بصورة مطبوعة وجاهزة، وهنا تبدأ المرحلة الثالثة والتي تسمى مرحلة التفسيرات والحلول فهنا يساعد المدرس الطلاب على توضيح كل ما هو مبهم ويجيب على تساؤلات الطلاب فيما يودو معرفته عن

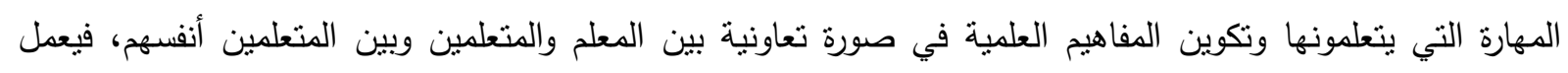

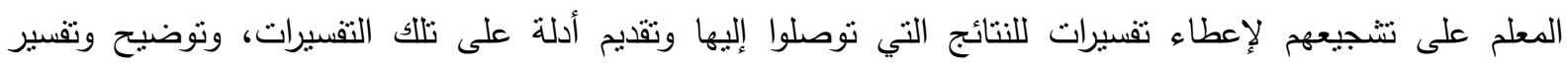
المفاهيم، وكذلك تشجيعهم على الاستفسار حول مدى صحة تلك التوضيحات والتفسيرات. اما المرحلة الأخيرة من مراحل هذا الأنموذج وهي مرحلة اتخاذ القرار فيكون الطلاب في هذه المرحلة قادرين على وضع التفسيرات والحلول حول ما كان

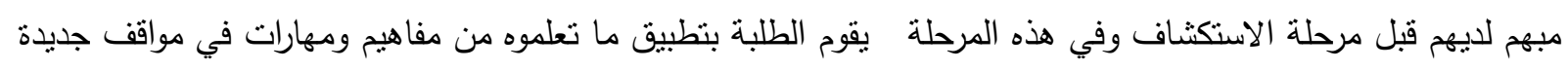
مشابهة، وربط ما تعلموه بأفكار وخبرات ومواقف أخرى تتعلق بموضوع الدرس أو النشاط. 


\section{مجلة التربية الرياضية - المجله (32) - العدد (2) - سنة 2020.}

اما المجموعة التجريبية الثانية الظابطة فقد تعلموا وفقاً لأسلوب التعليم الأعتيادي المتبع من قبل الدرس ويسمى

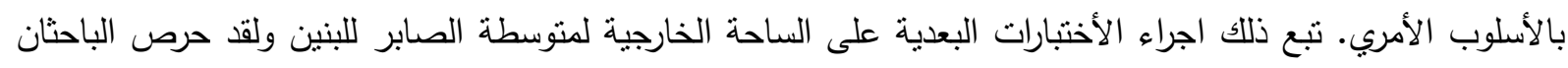

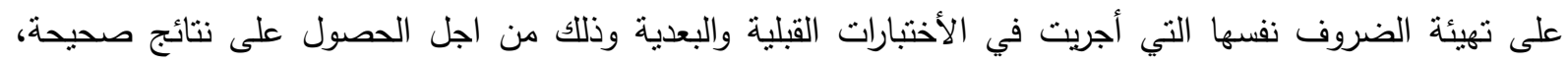
وإستعمل الباحثان الحقيبة الإحصائية (SPS) لمعالجة بيانات البحث عن طريق قوانين الوسط الحسابي، والإنحراف المعياري، والنسبة المئوية ، وإختبار (t.test) للعينات غير المستقلة.

النتائج:

الجدول (2) يين اختبار الفروق بين نتائج الأختبارين القبلي والبعدي للمجموعة التجريبية في اختبار الدحرجة

\begin{tabular}{|c|c|c|c|c|c|c|c|}
\hline \multirow{2}{*}{ مستوى الخطأ } & \multirow{2}{*}{ المحسوبة } & \multirow{2}{*}{ فَ } & \multicolumn{2}{|c|}{ الإختبار البعدي } & \multicolumn{2}{|c|}{ الإختبار القبلي } & \multirow{2}{*}{ المتغيرات } \\
\hline & & & $\varepsilon$ & س & $\varepsilon$ & س & \\
\hline 0.05 & 3.068 & 1.030 & 0.674 & 6.966 & 1.286 & 5667 & الدحرجة \\
\hline
\end{tabular}

معنوي > 0.05. درجة الحرية (9)

الجدول (3) يبن اختبار الفروق بين نتائج الأختبارين القبلي والبعدي للمجموعة الضابطة في اختبار الدحرجة

\begin{tabular}{|c|c|c|c|c|c|c|c|}
\hline \multirow{2}{*}{ مسنوى الخطأ } & \multirow{2}{*}{ المحسوبة } & \multirow{2}{*}{ فَ } & \multicolumn{2}{|c|}{ الإختبار البعدي } & \multicolumn{2}{|c|}{ الإختبار القبلي } & \multirow{2}{*}{ المتغيرات } \\
\hline & & & $\varepsilon$ & س - س & $\varepsilon$ & س - س & \\
\hline 0.03 & $3.978-$ & 0.500 & 0.718 & 6.200 & 0.908 & 5.700 & الدحرجة \\
\hline
\end{tabular}

معنوية > 0.05. درجة الحرية (9)

الجدول (4) يبين اختبار الفروق بين المجموعتين الظابطة والتجريبية لأختبار الدحرجة الأختبار البعدي

\begin{tabular}{|c|c|c|c|c|c|c|}
\hline \multirow{2}{*}{ الخطأ } & \multirow{2}{*}{ المحسوبة } & \multicolumn{2}{|c|}{ المجموعة الضابطة } & \multicolumn{2}{|c|}{ المجموعة التجريبية } & \multirow{2}{*}{ المتغيرات } \\
\hline & & $\varepsilon$ & س & $\varepsilon$ & س & \\
\hline 0.000 & 16.023 & 0.718 & 6.200 & 0.674 & 6.966 & الدحرجة \\
\hline
\end{tabular}

معنوية > 0.05. درجة الحرية (18)

الجدول (5) يبين اختبار الفروق بين المجموعتين الظابطة والتجريبية لأختبار التحصيل المعرفي في الأختبار البعدي

\begin{tabular}{|c|c|c|c|c|c|}
\hline مستوى الخطأ & قيمة ت المحسوبة & $\varepsilon$ & س & المجموعات & الاختبار \\
\hline \multirow{2}{*}{0.005} & \multirow{2}{*}{6.575} & 1.173 & 27.400 & التجريبية & \multirow{2}{*}{ المعرفي } \\
\hline & & 1.135 & 21.200 & الضابطة & \\
\hline
\end{tabular}

معنوية > 0.05. درجة الحرية (18)

المناقشة:

يتضح لنا عن طريق النتائج المعروضة في الجداول رقم ( 2-3-4) نجد إن هناك فرقاً معنوياً في الإختبارين القبلي و البعدي للمجموعة التجريبية و المجموعة الضابطة و لصالح المجموعة التجريبية في اختبار الدحرجة، ويعزو الباحثان

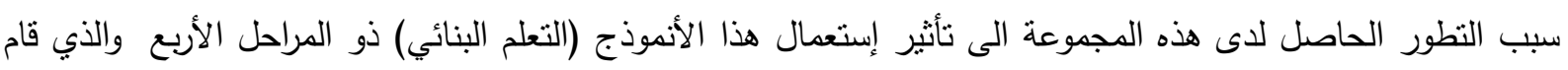

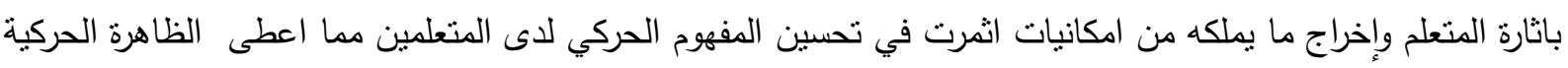

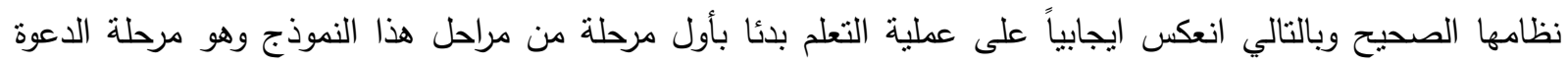


والذي يبدأ بحوار المعلم مع المتعلمين حول المفهوم المراد تعلمه والمفاهيم السابقة التي كان قد تعلمها الطلاب والتي لها علاقة بالمفهوم الحالي وصولا الى المرحلة الثانية وهي استكثاف المهارة وهنا تم تحفيزه على التعلم والتفاعل مع المهارة الجديدة وهذا ما يؤكده (زيتون و زيتون، 2003، صفحة 202) بأن الطلاب يتفاعلون مباشرة مع الخبرات الجديدة والتي من شأنها أن تثير عدداً من التساؤلات التي تحتاج إلى جواب وذلك من خدون، خلال قيامهر بالأنشطة سواء الفردية أو الجماعية وأثناء عملية البحث يتم اكتثاف أثنياء لم تكن معروفة لديهم من قبل ، وصولا للمرحلة الثالثة وهي مرحلة التفسيرات

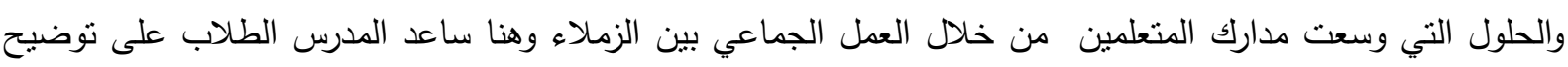
كل ما هو مبهم وأجاب على تساؤلات الطلاب فيما يودو معرفته وتطبيقه عمليا فيما يخص المهارة التي يتعلمونها و تكوين

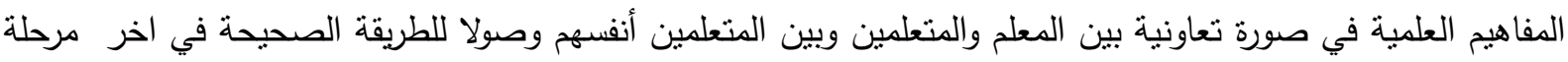
من مراحل هذا الأنموذج وهي اتخاذ القرار وهنا كان المتعلم قد وصل الى اتساع مدى فهمه للمهارات قيد التعلم وهذا يتفق مع ما أوردته (بطرس، 2004، صفحة 167) في أهمية وضوح خطوات التعلم فضلا عن طبيعة عرض المادة العلمية

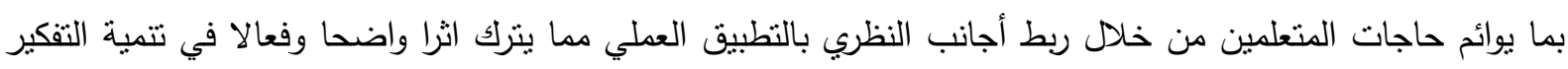
الأستدلالي لاى الطلاب ، اذ يساعدهم على زيادة إمكانيتهم المعرفية والمهارية بحيث يكون من السهل عليهم القيام

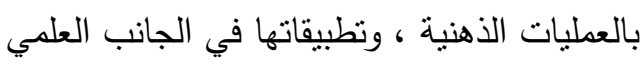
ويثير الباحثان الى أن هذا التحول والتميز لدورة التعلم الى انبثاقها من النظرية البنائية التي تركز على المتعلم ونشاطه

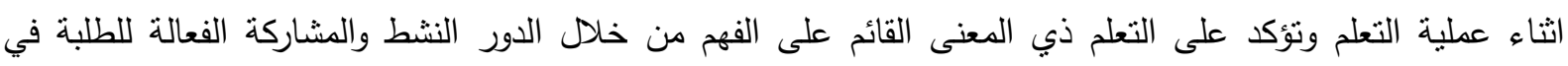
الأنشطة التي يؤدونها بهدف بناء مفاهيمهم ومعارفهم العلمية(rdoerr \& lesh , 2003) وعن طريق النتائج المعروضة في الجدول رقم (5) يتضح لنا أنَّ هناك فرقاً معنوياً في الإختبار البعدي بين المجموعة الضابطة والمجموعة التجريبية ولصالح المجموعة التجريبة في إختبار التحصيل المعرفي. ويعزو الباحثان سبب هذا التطور الحاصل الى تأثير إستعمال انموذج التعلم البنائي و الذي أدى الى تتمية قدر كبير من المهارات العقلية التي تركز على فئ نحو أساسي على البحث عن المعلومات والتقصي عنها و تحليلها و تتظيمها وتذكرها وكذلك حسن التطبيق لمكونات هذه

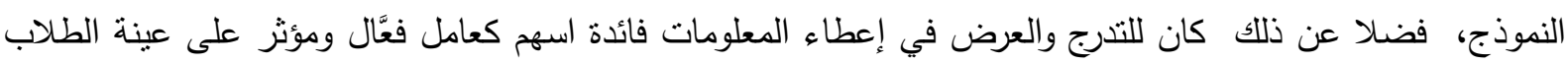

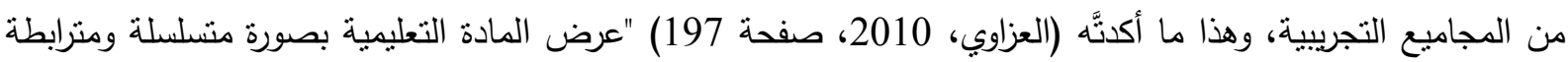
من العام الى التفاصيل و تقسيم المحتوى على مستويات يزيد من كفاية المتعلم للتعلم و تحفز قدراته العقلية الى البحث عن الته

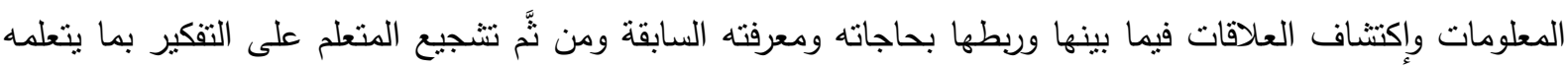

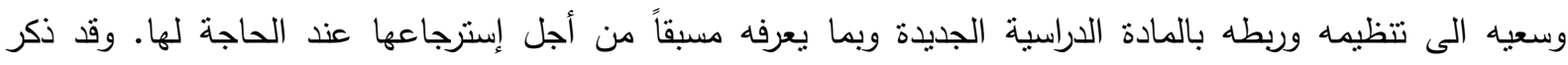
(بطاينة، 2013، صفحة 232) ان كافة المهارات الحركية سواء كانت أساسية ام رياضية انما هي مهارات ادراكية حسية ذات طبيعة معرفية تعتمد بالأساس على المعلومات التي تستقبلها الأعضاء الحسية ثم تتقلها الى الدماغ الذي يقوم

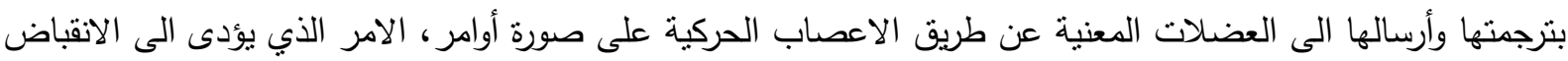

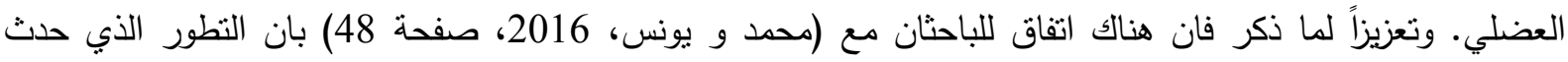
للمجموعات التجريبية في أداء المهارات يعود إلى أن المتعلم يعتمد على الخبرات المكتسبة والتكرار وصولاً إلى مران مرحلة

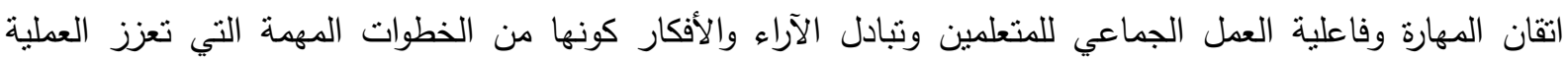
التعليمية ويتفق مع ما ذكره (صبري، 2006، صفحة 277) الى انه من خلال تبادل الحوار والتساؤلات والأفكار المقتبسة صنية والمعروضة من قبل المعلم يكون المتعلم ايجابياً ومشاركا وتبني العملية النعليمية بناءً صحيحاً قائماً على دور كل من فئل 
• إنّ لإستعمال (انموذج التعلم البنائي) أثز فعَّال في تتمية التحصيل المعرفي و تعلم مهارة الدحرجة بكرة القدم لدى عينة البحث. • يُمكن إعتماد انموذج التعلم البنائي في تعلم مهارة المناولة بكرة القدم و في نطوير التحصيل المعرفي لاى الطلاب كونه يشجع الطلاب على تقصي المعلومات و الحقائق و يجعل الطالب يفكر بالأداء قبل القيام به. • اعتماد انموذج التعلم البنائي في تتمية التحصيل المعرفي وتعلم مهارة الاحرجة بكرة القام. • إجراء دراسة ممانلة للاراسة الحالية على مهارات رياضية أخرى و ولئي على مراحل عمرية و دراسية مختلفة.

\section{المصادر}

ه احد سالم بطاينة. (2013). الإدرالك الحس حركي وعلاقته بالاحتفاظ بدقة الثبات الحركي. (مجلة دراسات العلوم

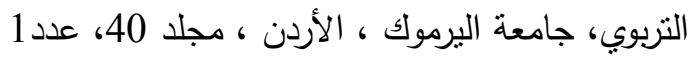
ازهار قاسم العزاوي. (2010). أثز إنموذجي مكارثي و رايجلوث في إكتساب المفاهيم العلمية و الإتجاه نحو مادة

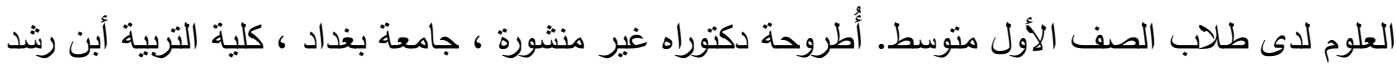

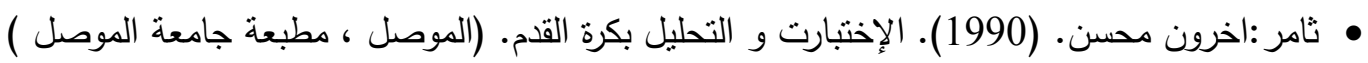
• حسن حسين زيتون، و عبد الحميد كمال زيتون. (2003). التعلم والتدريس من منظور النظرية البنائية. ط1 :(القاهرة، عالم الكتب) علي شامل. (2019). تأثثر دورة الذهن التعليمية الإككترونية وفق نموذجي كاربلس وبايبي في التحصيل المعرفي التعلم

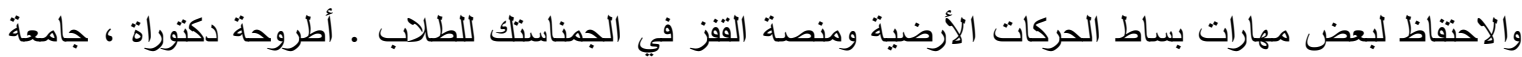
ديالى هلياء حسين ترف. (2014). استراتيجية التعلم البنائي لذوي التفكير الحاذق واثرها في التحصيل المعرفي وتعلم مهارتي

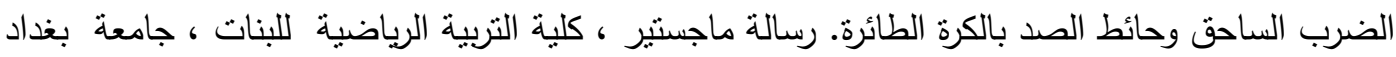

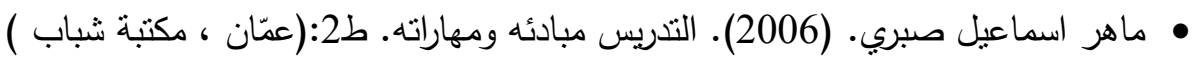
• محمد عبد الحسين عطيه (2005) ـ تأثثير نداخل التدريب الذهني والبدني المهاري بالأسلوبين المتسلسل والعشوائي في التعلم والأحتفاظ لبعض المهارات الأساسية بكرة القدم للمبتدئين ، أطروحة دكتوراة ، كلية التربية الرياضية ،جامعة

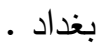

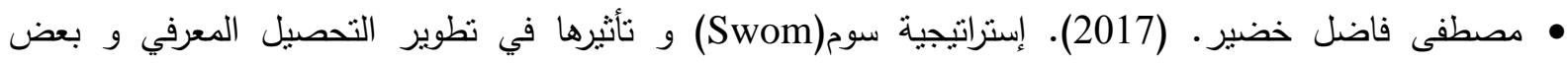
المهارات الأساسية بكرة القدم لطلاب الصف الرابع الإعدادي. رسالة ماجستير ، كلية التربية البدنية وعلوم الرياضة ، وامعة بغداد • ميثاق غازي محمد، و اسراء عبد الرضا يونس. (2016). نأثثر منهاج بايبي البنائي في نعليم بعض ذالمهارات

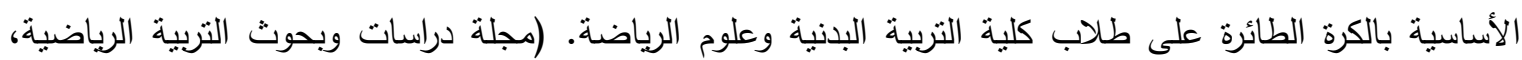
جامعة البصرة، العدد (48) • نضال منى بطرس. (2004). اثر استخدام نموذجي دورة التعلم والعرض المباشر في التحصيل وتتمية التفكير

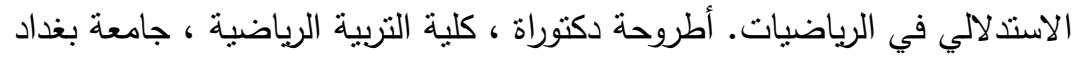

- lesh and rdoerr (2003) models and modeling perspectives on mathematics problem solving 
الملاحق

ملحق (1) نموذج من وحدة تعليمية للمجموعة التجريبية

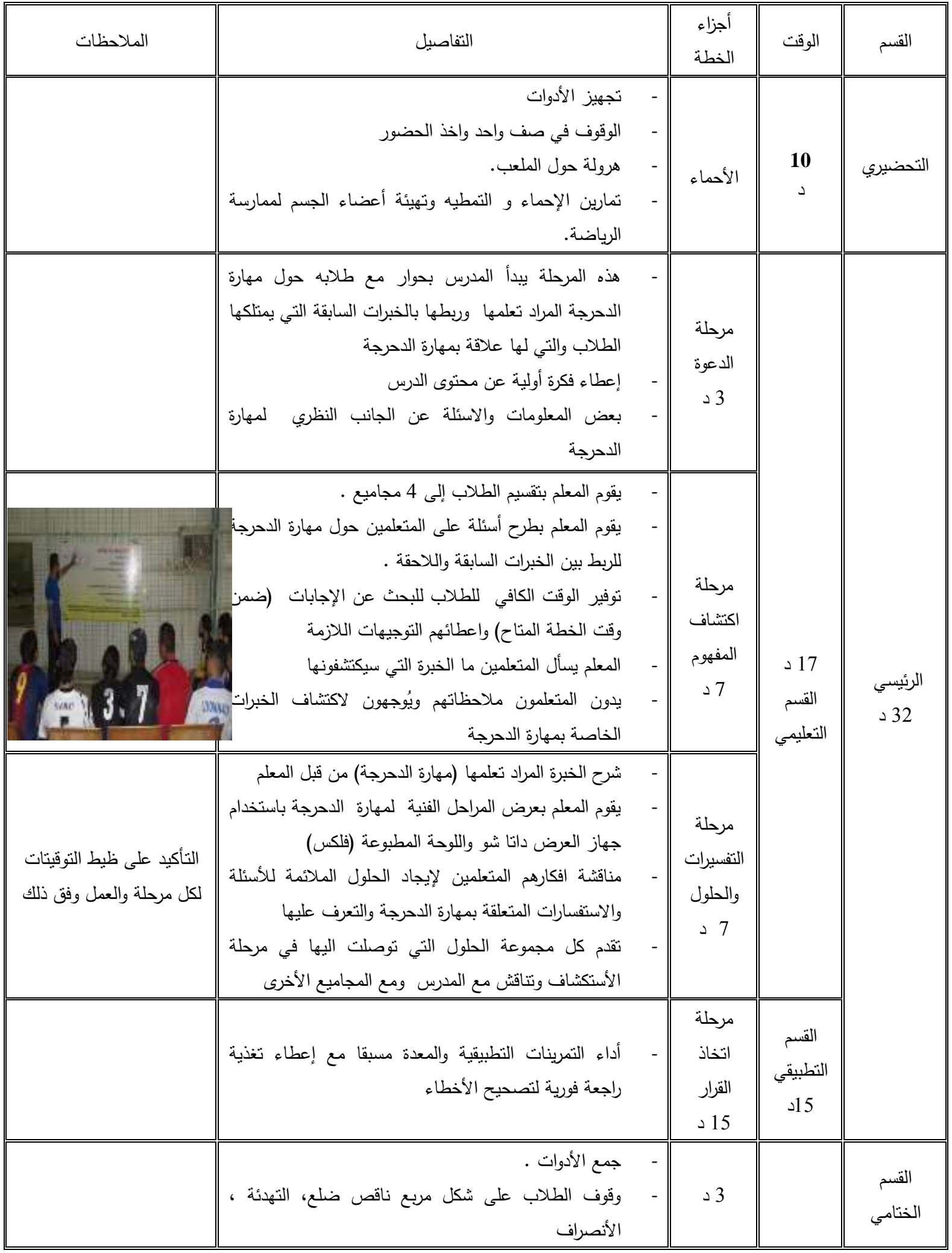


بين يديك أسئلة لإختبار التحصيل المعرفي يرجو منك الباحث قراءتها بعناية و الإجابة على الأسئلة أدناه بدقة مع ملاحظة ما يأني:-

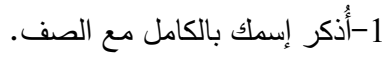

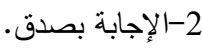

3-عدم ترك فقرة بدون إجابة.

4-وضع دائرة على الإجابة الصحيحة.

5-عدم الإستعانة بالزميل من أجل الإجابة.

شاكرين تعاونكم معنا

$$
\text { 1- أنواع الدحرجة بكرة القدم هي؟ التحرفي؟ }
$$

- - مدرجة الكرة بالجزء الخارجي و الداخلي و وجه القدم.

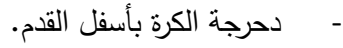

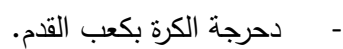

2- تهدف الدحرجة الى أغراض هي؟

- - - إجنياز المنافس و التخلص منه.

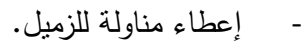

- - التهايف على المرمى.

3- من الأخطاء الثائعة في مهارة الدحرجة هي؟

- ركل الكرة بقوة زائدة مما يؤدي الى إبتعادها كثيراً عن رجل الناعب.

- - - - الدرجة تكون بشكل بطيء.

-

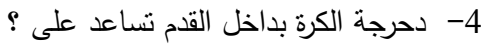

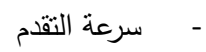

$$
\text { - - مينطيع التصويب بدقة }
$$

يحافظ على الكرة بين قدميه ويحكم السيطرة على خط سبر حركة الكرة

5- من الأخطاء الثائعة في الدحرجة ؟

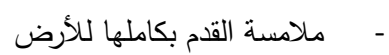

النظر غير موزع بين الكرة والملعب

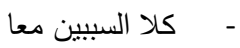

6- ان الدحرجة بخارج القدم يعد اكثر الأنواع شيوعا لماذا ؟

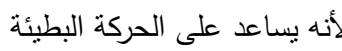

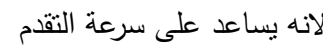

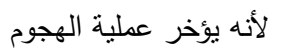

7- عند دحرجة الكرة في الهجوم المرتد السريع تكون الدحرجة ب ؟ لأبرم

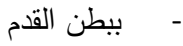

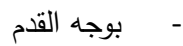

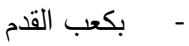

8- من اهم مهارات كرة القدم للمحافضة على الكرة والتتقل بها ؟

$$
\text { - }
$$

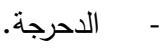

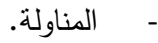

